\title{
Stability of Dispersible Aspirin Tablets Repacked into Dosette Boxes
}

\author{
Martina Mylrea, Sherryl Robertson, Alison Haywood, Beverley Glass
}

\begin{abstract}
Background: Although guidelines indicate that dispersible aspirin tablets should not be repacked into dose administration aids, it is common practice especially among older people.

Aim: To determine the stability of acetylsalicylic acid (ASA) in aspirin tablets repacked into Dosette boxes.

Method: Dispersible aspirin $300 \mathrm{mg}$ tablets were removed from their primary (foil) packaging, and repacked as whole and split (halved) tablets into Dosette boxes under 4 storage conditions: refrigeration $\left(2-8{ }^{\circ} \mathrm{C}\right)$, controlled room temperature $\left(25^{\circ} \mathrm{C} ; 60 \%\right.$ relative humidity $\left.[\mathrm{RH}]\right)$, accelerated $\left(40{ }^{\circ} \mathrm{C} ; 75 \%\right.$ $\mathrm{RH})$, and 'in-use' with natural variations in daylight exposure and internal temperature fluctuations $\left(23-26^{\circ} \mathrm{C} ; 45-60 \% \mathrm{RH}\right)$ for 1 week. The high performance liquid chromatography method developed was validated for accuracy, precision, linearity and range, sensitivity, robustness and specificity, and the suitability of extraction media evaluated.

Results: Linearity $\left(\mathrm{r}^{2}>0.999\right)$, precision (relative standard deviation $<2 \%$ ) accuracy (recovery: $95-102 \%$ ) and selectivity for the high performance liquid chromatography method were confirmed. The ASA content remained within specifications (95-105\% of labelled amount) for all except the accelerated storage condition, with $93 \%$ of the ASA remaining. The split tablets did not display any additional ASA degradation when compared to the whole tablets under the same conditions.

Conclusion: While the ASA content of the dispersible aspirin tablets remained within specifications at room temperature, there were changes in the physical appearance under accelerated storage conditions.
\end{abstract}

J Pharm Pract Res 2012; 42: 204-7.

\section{INTRODUCTION}

Dose administration aids (DAAs) have been developed to assist patients better manage their medicines by organising individual doses according to the prescribed dosing schedule throughout the day. ${ }^{1}$ While well-sealed devices, such as the WebsterPak are commonly used by community and hospital pharmacists, it is not known which DAAs are used by patients in their homes. Many of these aids, such as the Dosette box or pill organiser are readily available under a variety of brands but do not have adequate airtight seals. Removal of medicines from primary packaging and repacking into a DAA invalidates the stability guaranteed by the manufacturer. Only a small number of medicines (e.g. atenolol, paracetamol, prochlorperazine) have been investigated for stability

Martina Mylrea, BEd, BSc, Med (Learning Technology), Lecturer, Sherryl Robertson, BAppSc (Chem) Hons, PhD, Senior Technical Officer, School of Pharmacy and Molecular Sciences, James Cook University, Alison Haywood, BPharm, PhD, Senior Lecturer, School of Pharmacy, Griffith Health Institute, Griffith University, Beverley Glass, BSc (Chem) Hons, BTech (Marketing) Hons, BPharm, PhD, Chair, School of Pharmacy and Molecular Sciences, James Cook University, Townsville, Queensland

Corresponding author: Professor Beverley Glass, School of Pharmacy and Molecular Sciences, James Cook University, Townsville Qld 4811, Australia. E-mail: Beverley.Glass@jcu.edu.au following repacking into DAAs by pharmacists. ${ }^{2}$ Llewelyn et al. ${ }^{3}$ studied the stability of sodium valproate repacked into DAAs and stored under various temperature and humidity conditions. The results highlighted that accelerated conditions of temperature and humidity must be taken into account, as well as the fact that different countries and even within countries may experience variable temperature, humidity and light conditions. These studies have been performed using well sealed DAAs commonly used by pharmacies. ${ }^{2}$ Elmasry et al. $^{4}$ reported on the quantitative analysis of mebeverine, mesalazine, sulphasalazine and dispersible aspirin stored in a monitored dosage system, highlighting not only that the tablets were stored together, but also the differences in terms of safety and risk between medications repacked under the supervision of a pharmacist and those being repacked into DAAs by patients.

Low-dose aspirin is prescribed for primary prevention of stroke and acute myocardial infarction in older people. A recent study reported that low-dose aspirin (acetylsalicylic acid [ASA]) was a cost-effective option in primary prevention and that the majority of health systems are more than willing to pay for any additional quality-adjusted life year gained. ${ }^{5}$ Tablet splitting or dividing has been an accepted practice for many years as a means of obtaining the prescribed dose of a medication and for cost-saving purposes. ${ }^{6}$ The storage of split tablets is not well discussed in the literature and anecdotal evidence suggests that many patients split tablets in advance and then store these in bottles that previously contained the same medication, different medication or some other substance, or in a DAA, such as a Dosette box. ${ }^{6}$ Due to stability concerns, patients are generally advised that if only half a tablet is used, the unused half should be discarded, particularly with medicines that are known to be unstable when exposed to light and air. ${ }^{6}$

ASA is rapidly hydrolysed to salicylic acid (SA) on exposure to moisture and the limit of the SA content in dispersible ASA tablets is $3 \%$. $^{7}$ Chromatographic methods have been described to determine ASA in pharmaceutical formulations and biological fluids. ${ }^{8-21}$

Investigators using reverse-phase high performance liquid chromatography (HPLC) have recommended a short time limit for the determination of ASA between sample preparation and analysis in order to prevent degradation. The lack of exact data on the stability of these samples in an HPLC autosampler prior to analysis is the limitation of these assays. ${ }^{8-12,15-19,21}$ Kees et al. ${ }^{20}$, Gandhimathi et al. ${ }^{13}$ and Montgomery et al. ${ }^{14}$ have also been limited by their lack of specificity and data relating to robustness in terms of the stability of samples for HPLC injection. Other limitations include the use of mobile phases, which are complex and not cost effective, and the use of chloroform (environmentally inappropriate solvent) for the extraction of ASA. ${ }^{14,22}$ 
Considering the above repacking practices and that ASA is rapidly hydrolysed to SA on exposure to moisture, this study aimed to determine the stability of ASA in aspirin tablets repacked into Dosette boxes.

\section{METHOD}

\section{High Pressure Liquid Chromatography}

The Varian ProStar HPLC system consisted of a 240 quaternary solvent delivery module, 210 autosampler and a 330 photodiode array detector. A Pursuit XRs C18 (5 $\mu \mathrm{m}, 250 \times 4.6 \mathrm{~mm}$ ) reverse-phase column $\left(\right.$ at $40{ }^{\circ} \mathrm{C}$ ) was selected as the stationary phase. The mobile phase was water (Millipore Milli-Q plus water purification system):methanol:phosphoric acid (Ajax Chemicals) $1 \mathrm{M}$ (35:60:5) and the detection wavelength was $235 \mathrm{~nm}$. An injection volume of $20 \mu \mathrm{L}$ was used with a flow rate of 1 $\mathrm{mL} / \mathrm{min}$. Data were analysed using Varian Star Chromatography Workstation (version 6.41). The method was validated for accuracy, precision, linearity and range, sensitivity, robustness (solution stability) and specificity.

\section{Storage Conditions}

The following four storage conditions were investigated: refrigeration $\left(2-8{ }^{\circ} \mathrm{C}\right)$; controlled room temperature $(25$ ${ }^{\circ} \mathrm{C} ; 60 \%$ relative humidity $\left.[\mathrm{RH}]\right)$; accelerated $\left(40{ }^{\circ} \mathrm{C} ; 75 \%\right.$ $\mathrm{RH}$ ) simulated by a climate chamber (Binder KBF 720 ) conformant to the International Conference on Harmonisation requirements; and 'in-use' with natural variations in daylight exposure and internal temperature fluctuations $\left(23-26{ }^{\circ} \mathrm{C} ; 45-60 \% \mathrm{RH}\right)$.

Dispersible aspirin $300 \mathrm{mg}$ tablets (Solprin, Reckitt Benckiser) whole and split (halved along the tablet score line) were removed from the primary (foil) packaging and immediately repacked into Dosette boxes and stored for 1 week at each of the four storage conditions. For the controls, Solprin $300 \mathrm{mg}$ tablets in primary (foil) packaging) were also stored under the same four conditions. All of the Solprin tablets tested had the same batch numbers and an expiry date of 1 year from the time of analysis. The stored tablets were tested for drug content (ASA) and the degradation product (SA) at Days 0 and 7.

\section{Standard and Sample Solutions}

Standard solutions of ASA $(2-30 \mu \mathrm{g} / \mathrm{mL})$ and SA (2-10 $\mu \mathrm{g} / \mathrm{mL}$ ) were prepared. For each assay (in triplicate), 20 tablets were selected at random, removed from the primary packaging and finely crushed using a mortar and pestle. A sample equivalent to $300 \mathrm{mg}$ of aspirin was then transferred to a $50 \mathrm{~mL}$ volumetric flask and extracted with a solution of methanol:formic acid (98:2). Extracted tablet samples were sonicated for 3 minutes each and filtered through $0.2 \mu \mathrm{m}$ Acrodisc Premium Syringe filter (Pall Life Sciences). Further dilution with mobile phase resulted in a solution containing approximately $15 \mu \mathrm{g} / \mathrm{mL}$ aspirin. All samples were protected from light during extraction and stored in amber vials and analysed using the stabilityindicated HPLC method.

\section{RESULTS}

\section{High Pressure Liquid Chromatography}

Several extraction media (e.g. acetonitrile, methanol, ethanol, mobile phase) were evaluated to achieve the best extraction recovery of ASA. Single tablets (in triplicate) were dissolved in each extractant, filtered, diluted with mobile phase and analysed immediately. The
ASA per cent recovery for the extractants was: acetonitrile (80\%), methanol (99\%), ethanol (95\%) and mobile phase (water:methanol:phosphoric acid 35:60:5) (95\%). Methanol produced the best extraction recovery, and the addition of formic acid 2\% (Ajax Chemicals) improved the peak shape.

\section{Accuracy}

Accuracy was established using nine determinations for three concentrations across the calibration range for each analyte (ASA 5, 15 and $25 \mathrm{mg} / \mathrm{mL}$; SA 1, 3 and $6 \mathrm{mg} / \mathrm{mL}$ ). Per cent recoveries for ASA ranged from $99 \%$ to $101 \%$ and $98 \%$ to $104 \%$ for SA.

\section{Precision}

From the standard stock solutions for ASA and SA, ten determinations were undertaken at $100 \%$ of the analyte concentration. Relative standard deviation (\%RSD) values were $1 \%$ and $3 \%$ for ASA and SA respectively, establishing the method precision.

\section{Linearity and Range}

A calibration curve characterised by seven concentrations was established for ASA (range 2-30 mg/ $\mathrm{mL}$ ). Correlation coefficients greater than 0.9999 were consistently achieved. Linearity was assessed over 5 days resulting in a $\%$ RSD of $2 \%$ for the slope indicating a good correlation between the analyte concentration and peak areas. The analysis of SA similarly involved a calibration curve defined at seven concentration, starting above the limit of quantitation (LOQ) at $0.5 \mathrm{mg} / \mathrm{mL}$. Linearity was monitored over 5 days, with the correlation coefficient consistently exceeding 0.9999 and a \%RSD of $4 \%$.

\section{Sensitivity}

The limit of detection (LOD) and LOQ for the SA impurity determined using the signal-noise method were $0.00001 \%$ $\mathrm{w} / \mathrm{v}$ and $0.00003 \% \mathrm{w} / \mathrm{v}$ respectively, with the $\% \mathrm{RSD}$ for 10 samples at the LOQ equal to $3 \%$.

\section{Robustness (Solution Stability)}

Due to the susceptibility of ASA to hydrolysis, sample solutions can undergo degradation during extraction or sample preparation for HPLC analysis. This may be attributed to the water containing mobile phase and that the sample was maintained in the HPLC autosampler prior to analysis. Therefore, an assessment was made of the stability of the sample solutions prepared in the following manner. A tablet was extracted, diluted and maintained in the HPLC autosampler under laboratory conditions $\left(25 \pm 2{ }^{\circ} \mathrm{C}\right)$, it was then repeatedly analysed by HPLC over 8 hours. Extracted tablet sample solutions on the HPLC autosampler when subjected to repeat sampling after 5 hours showed a $2 \%$ decrease in concentration of the analyte, ASA. These results informed all analyses, where samples were always extracted, diluted and analysed within the 5-hour time period and usually within 2 hours to ensure stability of the analyte.

\section{Specificity}

As per International Conference on Harmonisation guidelines, forced degradation studies were performed on tablet samples under the stress conditions of light, heat, humidity, acid/base hydrolysis and oxidation as 


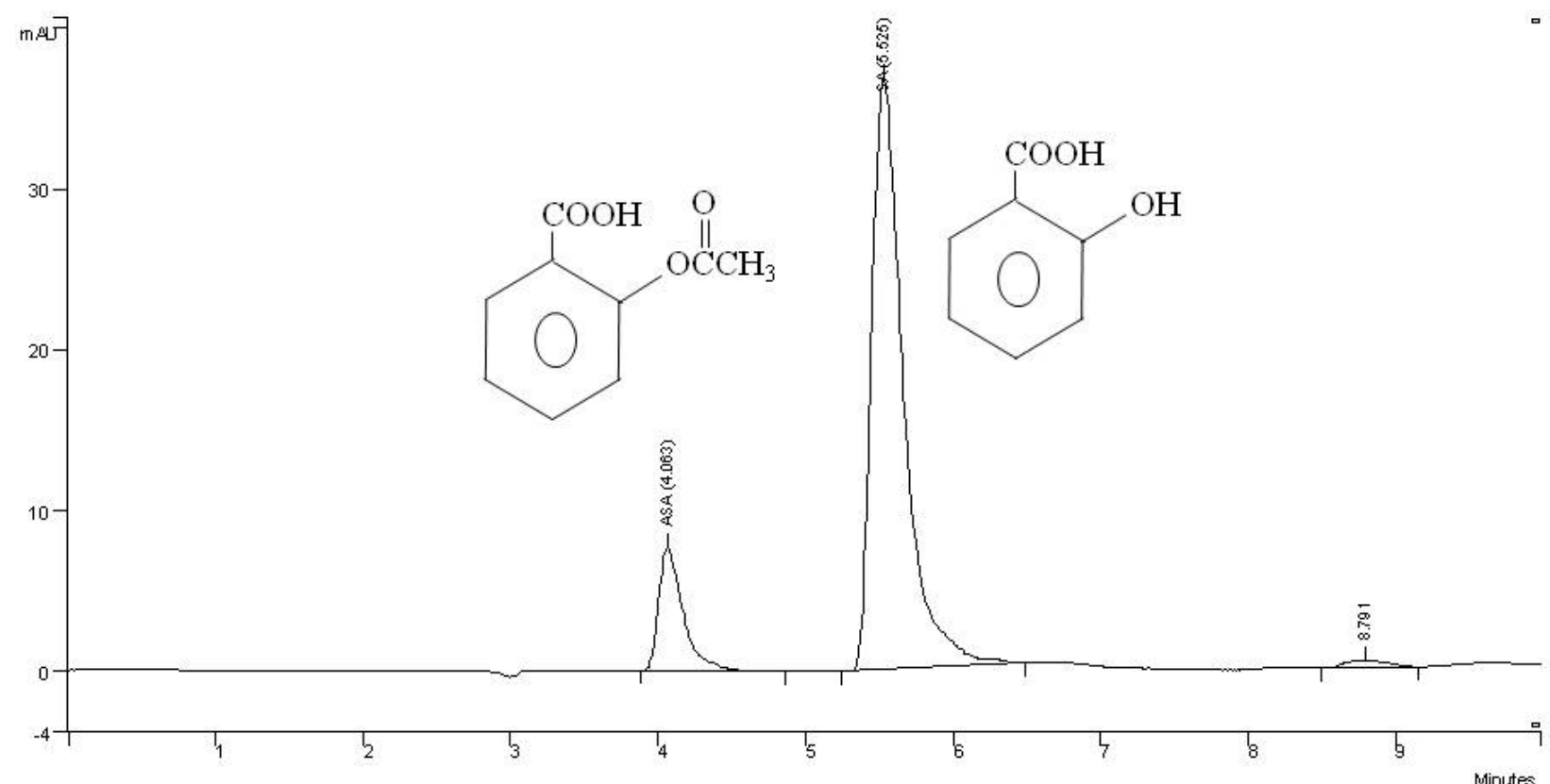

Figure 1. Chromatogram of the sample of ASA-containing tablets subjected to degradation in base (NaOH $1 \mathrm{M}$ ).

follows: acid $\left(\mathrm{HCl} 1 \mathrm{M}\right.$ at room temperature $\left[25 \pm 2{ }^{\circ} \mathrm{C}\right]$ for 4 hours); base $(\mathrm{NaOH} 1 \mathrm{M}$ at room temperature for 1 hour); oxidation $\left(\mathrm{H}_{2} \mathrm{O}_{2} 6 \%\right.$ at room temperature for 24 hours); and light (visible: 400 to $800 \mathrm{~nm}$ at 2.4 million lux $\mathrm{h}$; UV: 300 to $400 \mathrm{~nm}$ at 400 watt $\mathrm{h} / \mathrm{m}^{2}$ ) (Atlas Hereaus Suntest CPS + , Biolab). ${ }^{23}$ An ASA reference standard solution was also degraded under the same conditions. The conditions used in this study were designed to avoid complete, but achieve no less than 5\% degradation of the active pharmaceutical ingredient, ASA.

Other than SA, no major degradation products were observed, when ASA was subjected to acid/base, oxidative and photolytic stress. A representative chromatogram obtained from the sample of ASAcontaining tablets subjected to degradation in base $(\mathrm{NaOH} 1 \mathrm{M})$ is depicted in Figure 1. A summary of the amount of ASA remaining after exposure to various stress conditions of light, heat, humidity, acid/base hydrolysis and oxidation is presented in Table 1. Peak purity test results confirmed that the ASA peak was homogeneous and pure in all the analysed stress samples, confirming that the ASA was unaffected by the presence of the degradant SA or tablet excipients.
Table 1. Summary of forced degradation results

\begin{tabular}{lcc}
\hline Stress condition & Time & Assay of ASA \\
\hline Acid hydrolysis ( $\mathrm{HCl} 1 \mathrm{M})$ & 4 hours & $91 \%$ \\
Base hydrolysis ( $\mathrm{NaOH} 1 \mathrm{M})$ & 1 hour & $34 \%$ \\
Oxidation $\left(\mathrm{H}_{2} \mathrm{O}_{2} 6 \%\right)$ & 24 hours & $8 \%$ \\
Photolytic degradation & - & $78 \%$ \\
UV (300 to $400 \mathrm{~nm})$ & 400 watt h/m ${ }^{2}$ & - \\
VIS (400 to $800 \mathrm{~nm})$ & 2.4 million lux h & - \\
\hline
\end{tabular}

ASA $=$ acetylsalicylic acid. $\mathrm{UV}=$ ultraviolet. $\mathrm{VIS}=$ visible.

\section{Storage Conditions}

Aspirin is rapidly hydrolysed to SA on exposure to moisture and the limit of SA content in aspirin tablets is prescribed by the British Pharmacopoeia (BP) to be $0.0006 \% \mathrm{w} / \mathrm{v} .^{7}$ Aspirin content is required to be within $95 \%$ to $105 \%$ of the labelled amount. ${ }^{7}$

The dispersible aspirin tablets kept in the primary packaging and stored under the four storage conditions retained potency with no significant degradation to SA. All tablets repacked into Dosette boxes, except those tablets stored at accelerated conditions complied with

Table 2. Effect of exposure to various storage conditions on the stability of ASA in repacked dispersible aspirin tablets

\begin{tabular}{|c|c|c|c|c|c|}
\hline \multirow[b]{2}{*}{ Storage condition } & \multirow[b]{2}{*}{ Packaging } & \multicolumn{2}{|c|}{ Mean \% ASA remaining $(\mathrm{SD}, \mathrm{n}=3)$} & \multicolumn{2}{|c|}{ Mean \% SA $(n=3)$} \\
\hline & & Whole tablet & Split tablet & Whole tablet & Split tablet \\
\hline $\mathrm{t}=0$ & - & $101 \pm 0.2$ & - & $<0.005^{*}$ & - \\
\hline $25^{\circ} \mathrm{C} ; 60 \% \mathrm{RH}$ & Dosette box & $100 \pm 0.4$ & $103 \pm 0.3$ & 0.2 & 0.2 \\
\hline $25^{\circ} \mathrm{C} ; 60 \% \mathrm{RH}$ & Original foil & $100 \pm 0.1$ & - & $<0.005$ & - \\
\hline $40{ }^{\circ} \mathrm{C} ; 75 \% \mathrm{RH}$ & Dosette box & $93 \pm 0.6$ & $91 \pm 0.1$ & 6.7 & - \\
\hline $40{ }^{\circ} \mathrm{C} ; 75 \% \mathrm{RH}$ & Original foil & $101 \pm 0.03$ & - & $<0.005$ & - \\
\hline 'In-use' & Dosette box & $100 \pm 0.1$ & $99 \pm 0.3$ & 0.5 & - \\
\hline 'In-use' & Original foil & $102 \pm 0.1$ & - & $<0.005$ & - \\
\hline Refrigeration $\left(5 \pm 3^{\circ} \mathrm{C}\right)$ & Dosette box & $100 \pm 0.1$ & $100 \pm 0.2$ & 0.2 & - \\
\hline Refrigeration $\left(5 \pm 3{ }^{\circ} \mathrm{C}\right)$ & Original foil & $101 \pm 0.3$ & - & $<0.005$ & - \\
\hline
\end{tabular}

ASA = acetylsalicylic acid. $\mathrm{BP}=$ British Pharmacopoeia. $\mathrm{RH}=$ relative humidity. $\mathrm{SA}=$ salicylic acid.

*As determined by the limit of quantitation $(0.3 \mathrm{~g} / \mathrm{mL})$. 
the BP requirement that the aspirin content should be within $95 \%$ to $105 \%$ of the labelled amount (Table 2). This highlights that both temperature and moisture accelerate the degradation of aspirin.

There is concern that the content of the degradant SA exceeded the BP limit (3\%) for the accelerated storage conditions for the aspirin tablets repacked into Dosette boxes. The accelerated storage condition showed SA to be present in more than double $(6.7 \%)$ the specified limit (Table 2). For all other storage conditions the amount of SA did not exceed the limit. However, when compared to the results for the original packaging, a greater percentage of SA was present.

No additional degradation was associated with splitting tablets, with similar results for the ASA and SA content across the four storage conditions. Slight differences in concentration between whole and split tablets may be due to slight inaccuracies in splitting which was done manually along the tablet score line.

With regards to the physical attributes, the aspirin tablets removed from the original packaging exhibited signs of physical degradation within 7 days of being repacked into Dosette boxes and stored at accelerated conditions. The tablets swelled, became soft, disintegrated easily and developed a pink discoloration.

\section{DISCUSSION}

A simple and cost-effective HPLC method was developed to quantitate ASA in dispersible aspirin tablets that is accurate, precise, sensitive and specific. The extraction method using methanol resulted in an extraction recovery of $99 \%$ and was superior to other solvents. In addition, methanol presented an environmentally safe option compared to chloroform used by Montgomery et al. ${ }^{14}$ Our study also presents important information on the robustness of the HPLC method, which ensures the stability of ASA in the samples prior to analysis. This stability-indicating method can be used to determine ASA in dispersible aspirin tablets repacked into Dosette boxes.

Although our results concur with Elmasry et al. ${ }^{4}$ in terms of the aspirin content when stored under standard conditions, they did not specify the exact temperature conditions, conduct the stability study under accelerated conditions, or monitor the amount of the degradant, SA. However, they highlighted the risk associated with patients using Dosette boxes to manage medicines and their work presents a valuable insight into the implications of storing medicines together. These results are also in agreement with the findings of a study highlighting that discoloration in aspirin tablets was due to exposure to high humidity. ${ }^{24}$ Dispersible tablets are listed as an example of solid dosage forms that should not be repacked into compliance aids, according to guidelines, such as the Professional Practice Standards and Dose Administration Aids Service. ${ }^{25,26}$ A flow chart for the quality management of DAAs in practice has also been outlined in a recent article to provide guidance for pharmacists when repacking medicines into DAAs. ${ }^{27}$

In conclusion, while the ASA content of the dispersible aspirin tablets remained within specifications at room temperature, there were changes in the physical appearance under accelerated storage conditions.

Competing interests: None declared

\section{References}

1. Department of Health and Ageing. Guiding principle 3: dose administration aids. In: Guiding principles for medication management in the community, Canberra: Department of Health and Ageing; 2006.

2. Glass BD, Haywood A, Llewelyn V, Mangan M. Compliance aids and medicine stability: new evidence of quality assurance. Curr Drug Saf 2009; 4: 74-8.

3. Llewelyn VK, Mangan MF, Glass BD. Stability of sodium valproate tablets repackaged into dose administration aids. J Pharm Pharmacol 2010; 62: 83843.

4. Elmasry MS, Blagbrough IS, Rowan MG, Saleh HM, Kheir AA, Rogers PJ. Quantitative HPLC analysis of mebeverine, mesalazine, sulphasalazine and dispersible aspirin stored in a Venalink monitored dosage system with coprescribed medicines. J Pharm Biomed Anal 2011; 54: 646-52.

5. Annemans L, Wittrup-Jensen K, Bueno H. A review of international pharmacoeconomic models assessing the use of aspirin in primary prevention. J Med Econ 2010; 13: 418-27.

6. Marriott JL, Nation RL. Splitting tablets. Aust Prescr 2002; 25: 133-5.

7. British Pharmacopoeia Commission. Formulated preparations: specific monographs - aspirin tablets. In: British Pharmacopoeia 2012. Vol. 3. London: The Stationery Office; 2011.

8. Kmetec V. Simultaneous determination of acetylsalicylic, salicylic, ascorbic and dehydroascorbic acid by HPLC. J Pharm Biomed Anal 1992; 10: 1073-6. 9. Nozal MJ, Bernal JL, Toribio L, Jimenez JJ, Martin MT. Validation of the removal of acetylsalicylic acid. Recovery and determination of residues on various surfaces by high performance liquid chromatographic. J Chromatogr A 2000; 870: 69-75.

10. Al-Gohary OM, Al-Kassas RS. Stability studies of aspirin-magaldrate double layer tablets. Pharm Acta Helv 2000; 74: 351-60.

11. Fogel J, Epstein P, Chen P. Simultaneous high-performance liquid chromatography assay of acetylsalicylic acid and salicylic acid in film-coated aspirin tablets. J Chromatogr 1984; 317: 507-11.

12. Franeta JT, Agbaba D, Eric S, Pavkov S, Aleksic M, Vladimirov S. HPLC assay of acetylsalicylic acid, paracetamol, caffeine and phenobarbital in tablets. Farmaco 2002; 57: 709-13.

13. Gandhimathi M, Ravi TK, Abraham A, Thomas R. Simultaneous determination of aspirin and isosorbide 5-mononitrate in formulation by reversed phase high pressure liquid chromatography. J Pharm Biomed Anal 2003; 32: 1145-8.

14. Montgomery ER, Taylor S, Segretario J, Engler E, Sebastian D. Development and validation of a reversed-phase liquid chromatographic method for analysis of aspirin and warfarin in a combination tablet formulation. J Pharm Biomed Anal 1996; 15: 73-82.

15. Torrado S, Torrado S, Cadorniga R. Comparison of assay methods by secondderivative spectroscopy, colorimetry and fluorescence spectroscopy of salicylic acid in aspirin preparations with a high-performance liquid chromatographic method. J Pharm Biomed Anal 1994; 12: 383-7.

16. Verstraeten A, Roets E, Hoogmartens J. Quantitative determination by highperformance liquid chromatography of acetylsalicylic acid and related substances in tablets. J Chromatogr 1987; 388: 201-16.

17. Wang C, Vickers TJ, Mann CK. Direct assay and shelf-life monitoring of aspirin tablets using Raman spectroscopy. J Pharm Biomed Anal 1997; 16: 8794.

18. Wouters I, Roets E, Hoogmartens J. Analysis of tablets containing acetylsalicylic acid and phenylephrine by high-performance liquid chromatography. J Pharm Biomed Anal 1984; 2: 481-90.

19. Cockaerts P, Roets E, Hoogmartens J. Analysis of a complex analgesic formulation by high-performance liquid chromatography with columnswitching. J Pharm Biomed Anal 1986; 4: 367-76.

20. Kees F, Jehnich D, Grobecker H. Simultaneous determination of acetylsalicylic acid and salicylic acid in human plasma by high-performance liquid chromatography. J Chromatogr B Biomed Appl 1996; 677: 172-7.

21. Pirola R, Bareggi SR, De Benedittis G. Determination of acetylsalicylic acid and salicylic acid in skin and plasma by high-performance liquid chromatography. J Chromatogr B Biomed Sci Appl 1998; 705: 309-15.

22. US Pharmacopeia - National Formulary (USP 34-NF 29) 2011 [2009].

Monographs: aspirin tablets. Rockville: US Pharmacopeial Convention; 2010.

23. ICH Expert Working Group. ICH harmonised tripartite guideline: validation of analytical procedures: text and methodology Q2(R1). Geneva: International Conference on Harmonisation of Technical Requirements for Registrataion of Pharmaceuticals for Human Use; 2005.

24. Yamazaki N, Taya K, Shimokawa K, Ishii F. The most appropriate storage method in unit-dose package and correlation between color change and decomposition rate of aspirin tablets. Int J Pharm 2010; 396: 105-10.

25. Pharmaceutical Society of Australia. Guidelines and standards for pharmacists: dose administration aids service. Deakin: Pharmaceutical Society of Australia; 2007.

26. Pharmaceutical Society of Australia. Standard 7: dose administration aids service. In: Professional practice standards: version 4. Deakin: Pharmaceutical Society of Australia; 2010.

27. Haywood A, Llewelyn V, Robertson S, Mylrea M, Glass BD. Dose administration aids: pharmacists' role in improving patient care. Australas Med J 2011; 4: 183-9.

Received: 15 May 2012

Revisions requested after external review: 23 July 2012

Revised version received: 27 July 2012

Accepted: 27 August 2012 